\title{
Numerical and experimental thermal analysis for the improvement of various types of windows frames and rolling-shutter boxes
}

\author{
Nicola Cardinale • Gianluca Rospi • \\ Tiziana Cardinale
}

Received: 2 July 2014/Accepted: 18 September 2014/Published online: 24 March 2015

(c) The Author(s) 2015. This article is published with open access at Springerlink.com

\begin{abstract}
Data provided by Italian Ministry of Environment say that in 5 years you consume, just for heating of an apartment, an amount of energy equal to that required for the all construction of the same apartment. The years come down to three if one includes other energy consumption. In terms of primary energy, the building-plant system is responsible for about $45 \%$ of the national energy demand. The rolling-shutter box system, in most cases, is the first responsible for thermal dispersions and input of free heat coming from outside. In addition, the window frames have the obligation of the CE marking to be sold on the free European market. Among the basic requirements, the thermal transmittance is the parameter responsible for the energy performance. The research concerned the energy study of different window frames and rolling-shutter boxes through the use of finite element methodology and experiments in situ. This study was carried out on six different types of windows frames (PVC, wood, and woodaluminium) and four different models of rolling shuttersboxes (all with structure made by expanded polystyrene). The experimental analysis allowed the comparison between the thermal transmittance values calculated according to the UNI EN ISO 10077-1/2 and measured in accordance with ISO 9869.
\end{abstract}

Keywords Experimental and thermal analysis - Thermal transmittance - Energy efficiency of windows frames and rolling-shutter boxes $\cdot$ Finite element analysis

N. Cardinale · G. Rospi $(\bowtie) \cdot$ T. Cardinale Department of European and Mediterranean Cultures: Architecture, Environment, Cultural Heritages (DICEM), University of Basilicata, Via Lazazzera, 75100 Matera, Italy e-mail: gianluca.rospi@gmail.com

\section{Introduction}

Improving the energy efficiency of the building and the indoor comfort is just some of the goals that the European Union aims to achieve by 2020 . In this sense, the EU has promoted various programs, projects and guidelines, such as 2002/91/EC, 2006/32/EC, and 2010/31/EU, which define addresses, tools, policies, and solutions in terms of energy efficiency of new and existing buildings.

"The EC marking indicates that the product complies with all the Community provisions which provide its use", from design to manufacture, placing on the market, putting into service of the product until its disposal. The EC marking governs the entire life cycle of the product from the time of placing on the market and it is governed by Directive 98/34/EC. With regard to the performance characteristics, the Directive 98/34/EC refers to harmonized European standards.

For the fixtures, the harmonized European standard is UNI EN 14351-1 [product standard] that specifies the performance characteristics of windows and external pedestrian doors and includes the framework of performance requirements, and test criteria necessary to ensure conformity with the essential requirements set by Directive 98/34/EC. It should be noted that, the civil sector, in Italy, representing over $40 \%$ of the national energy demand and recorded a progressive and inexorable growth of consumption. An Italian building expresses very low energy performance recording annual consumption, in terms of end use, that vary from $160 \mathrm{kWh} / \mathrm{m}^{2}$ per year to more than $230 \mathrm{kWh} / \mathrm{m}^{2}$ per year, compared with lower consumption between 30 and $60 \%$ within EU level. A so high energy consumption determines, as a result, values of annual emission of greenhouse gases well above the European average (19 million of installed boilers in Italy consume 
more than 25 Mtoe per year determining an emission of about 80 Mtonn of equivalent $\mathrm{CO}_{2}$ per year).

In the past couple of decades, the glass has been increasingly used in the architectures; and today the windows are a key material in façade technology. When employing windows in modern buildings, numerous physical aspects need to be considered such as visual contact between interior and exterior, use of daylight, optimizing and controlling solar energy gains, minimizing thermal losses, optimizing thermal comfort, noise protection, air and driving rain tightness, and fire safety. The area of the windows in the building envelope is approximately the $20 \%$ of the total area envelope and the overall heat losses through the windows is even more than four times higher than for the insulated building walls. One of the old methods of suppressing the heat losses through windows is the use of wooden shutter closed by night. Today, we use mostly the various types of blinds and among them e.g., the roller blinds mainly to provide shade, privacy and as well as the security (usually external roller blinds).

With regard to experimental studies in the field of windows, we focused on the following:

- An experimental study to determine the overall heat transfer coefficient of the double-glazed window without low-emission coating and the heat losses through window glazing that use roller blinds was published in $[1,2]$.

- In [3], we find a study on window shutters that using PCM material for reduce the heat gain by absorbing the heat gain before it reaches the indoor space. Instead in [4], the application results of a previous and current EU-project on super-insulating glazing based on monolithic silica aerogel were described.

- Some research on the effects of the geometric characteristics of the cavities of the aluminum frames and the emissivity properties of the cavity inner surfaces was published in [5].

- In $[6,7]$, the authors study the effect of the thermal transmittance and solar transmittance of some windows on the building thermal balance. In these studies, different climatic localities were considered. Instead in [8], the energy savings connected to the potential use of the reversible windows in several Italian locations for buildings with no-prevalent cooling or heating requirements were analyzed.

- In [9], we find a simple method for analyzing and discussing energy flows through glazing. This method is based on monthly mean values of interior-exterior temperature difference and solar irradiance, and it was implemented for eight case study locations in Europe namely Bucharest, London, Madrid, Moscow, Rome, Stockholm, Warsaw, and Zurich.
- In [10], the focus is on buildings in Greece describing the impact of glazing on energy consumption and comfort.

- In [11], the authors dealt with the role of geometry factors, such as window orientation, window to wall ratio, and room width to depth ratio, on building energy performance in a commercial office building. The analysis was developed on office buildings located in various climate zones.

- In [12], two different two-dimensional frame/spacer heat transfer calculation methodologies used in North America and in Europe were compared. The [12] shows algebraically that the differences between the ISO and ASHRAE methods turn out to be due to the way the corner regions of the window frame and glazing are treated for the evaluation of the thermal transmittance by two-dimensional calculations.

Analyzed window frame-rolling shutter box system

The system window frame and rolling-shutter box are on the border between outdoor and indoor space; it represents the view to the outside and the entry of natural light in indoor spaces and a point of discontinuity and of heat loss; so a good design provides an excellent protection of indoor environments from the elements of external environment.

According to the requirements of the municipal and sanitary building regulations, one of the necessary requirements for the habitability of indoor environments is that the window or French window of a room must provide at least an opening of 1/8 to the surface of the floor of the room itself.

In this work, different types of window frame and rolling-shutter box systems are analyzed. Specifically four different types of frames were studied, characterized by constructive material (PVC, wood, and, wood-aluminum) and four different types of rolling-shutter box made by EPS, characterized by construction type (different thicknesses of the polystyrene and different positions with respect to the window frame).

\section{Analyzed frames}

We analyzed two open joint typologies of PVC frames with frame with five air spaces of thickness $70 \mathrm{~mm}$ and shutter with seven air spaces of thickness from 70 to $80 \mathrm{~mm}$. The air space profiles, suitable to contain closed or C-shaped metal reinforcements of different thicknesses, is separated from the outside, so it does not ever come in contact with water or other atmospheric agents. The standard glass mounted on the windows is 4/20/4 (Fig 1a).

As regards, instead, the wooden frame analyzed, this is characterized by the construction typology by laminated wood of section $68 \times 78 \mathrm{~mm}$ both for the shutter and for 
the frame. The air between shutter and frame is $12 \mathrm{~mm}$, while the beating is $18 \mathrm{~mm}$. The wood is joined by means of tenons at $90^{\circ}$. The glass air space used is $4 / 20 / 4 \mathrm{~mm}$ (Fig 1b).

Finally, the wood-aluminum frame typology is characterized by the combination of two materials, laminated wood with section $68 \times 78 \mathrm{~mm}$ for shutter and frame, coated on the outside with an anodized aluminum profile pegged to the wood frame. The glass air space used is $4 / 20$ / $4 \mathrm{~mm}$ (Fig 1c).

While as regards to the rolling-shutter boxes, all four models are made by expanded polystyrene, said technically EPS. The EPS has a closed-cell structure composed of $98 \%$ air, which in addition to thermal insulation gives to this product property of vapor barrier.
In the past, the traditional rolling-shutter boxes represented weak points that often allowed leaks of cold and humidity. In the analyzed rolling-shutter boxes, these issues are resolved in a definitive way, through the use of polystyrene. The natural and continuous ventilation in the rolling shutter and the perfect closure between the box and the frame, prevent the formation of mold and condensation both in the box and inside the rooms. Among the four models analyzed, there are two with inspection by the front, called Simply Figs. 2 and 3 and two with inspection by the bottom, called Hyde Figs. 4 and 5.

The rolling-shutter boxes with front inspection Simply analyzed are characterized by having a structure in selfextinguishing expanded polystyrene of $30 \mathrm{~kg} / \mathrm{m}^{3}$ and a hatch composed of a removable panel in expanded
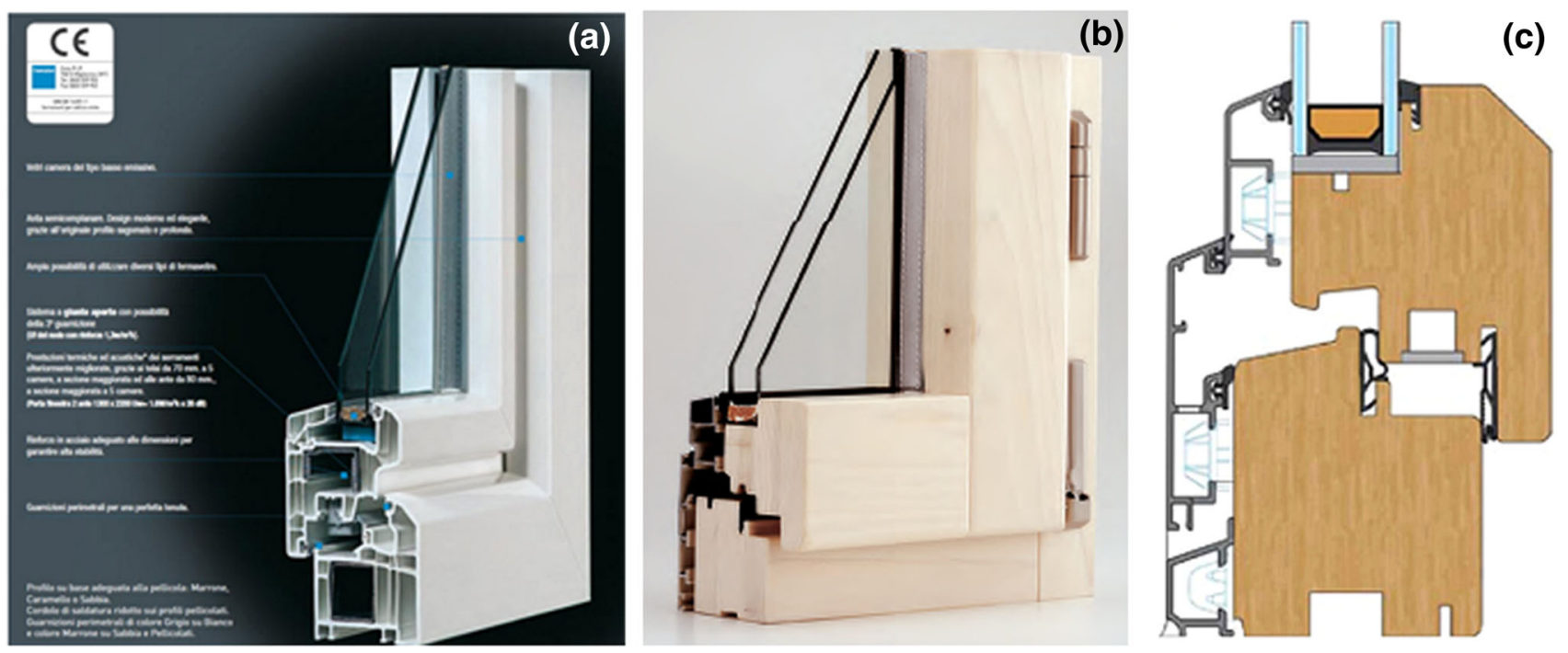

Fig. 1 Analyzed frame typologies a. PVC, b. Wood, c. Wood-Aluminum

Mortar, sand and cement with additives

Plaster anchoring grid

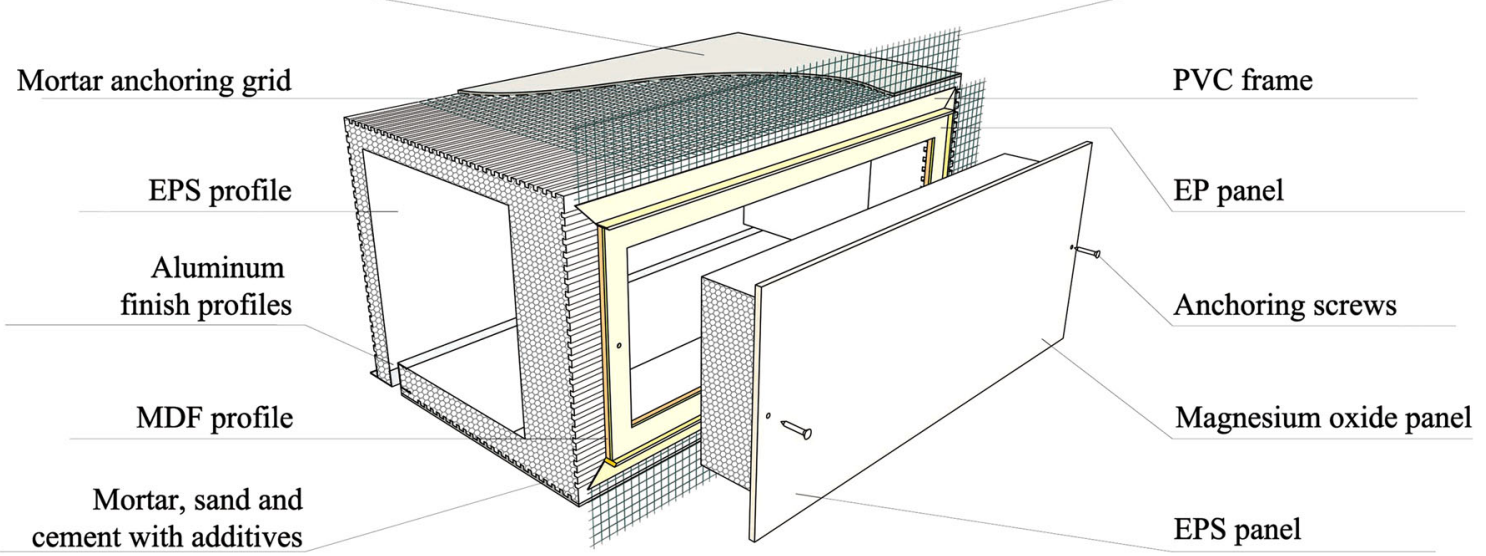

Fig. 2 Simply model assonometry 
polystyrene glued by polyurethane glues on a panel of magnesium oxide treatable with paints of water. Specifically, the two models were analyzed Simply 30 (characterized by having a thickness of $30 \mathrm{~mm}$ of EPS) and the model Simply 35 (characterized by having a thickness of $35 \mathrm{~mm}$ of EPS) both analyzed in two different con- (a)

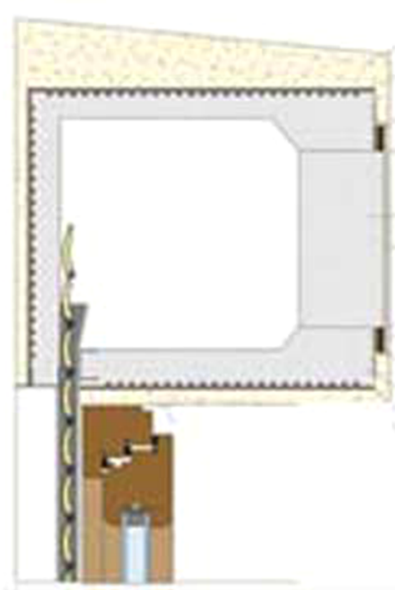

Plaster

Mortar, sand and cement with

EPS profile

PVC frame

EPS panel

Magnesium oxide panel

MDF profile

EP panel

PVC frame

EPS profile

Mortar, sand and cement with

Plaster

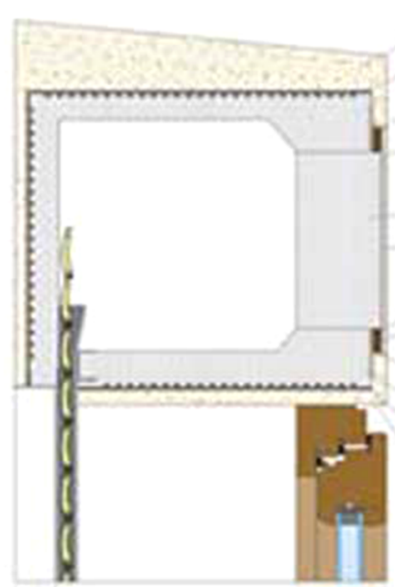

Plaster

(b)

Mortar, sand and cement with

EPS profile

additives

PVC frame

EPS panel

Magnesium oxide panel

MDF profile

EP panel

PVC frame

EPS profile

Mortar, sand and cernent with

Plaster additives

Fig. 3 Positioning window frame on rolling-shutter box: a outer edge, $\mathbf{b}$ inner edge

Fig. 4 Hyde model assonometry

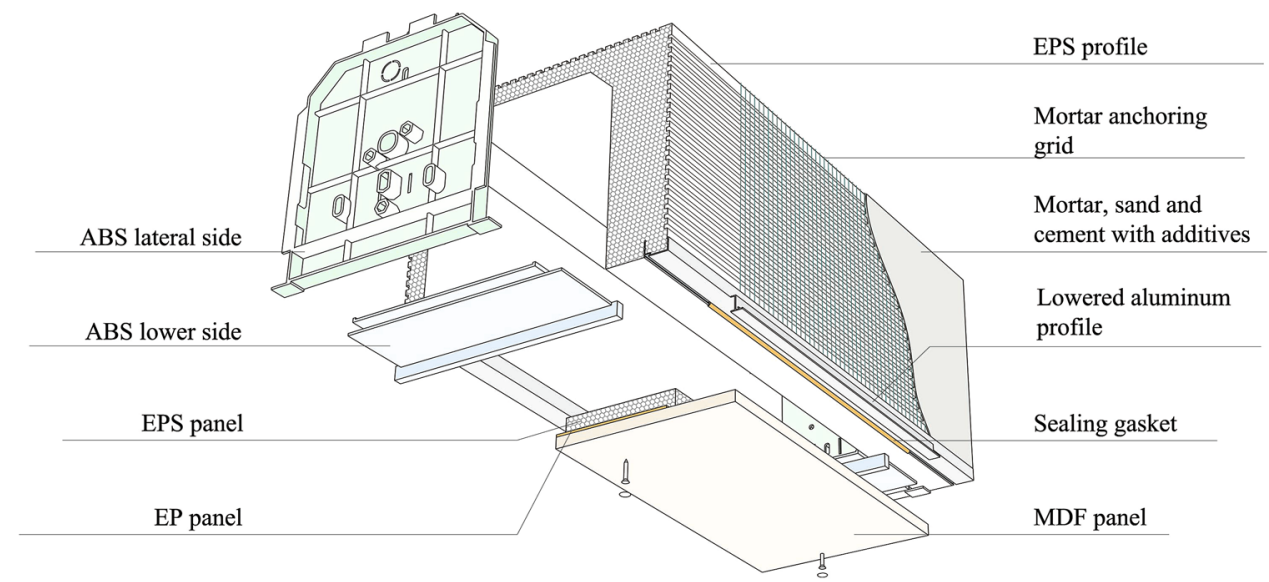

(a)

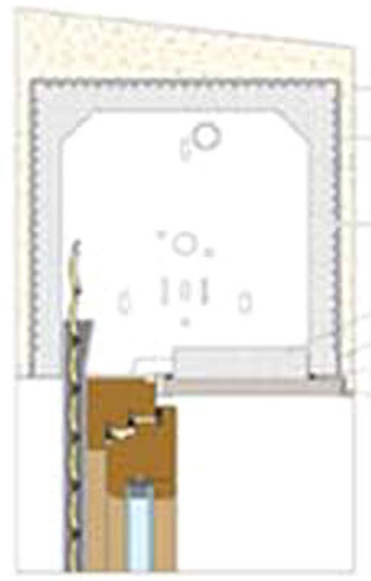

Plaster

Mortar, sand and cement with additives

EPS profile

EPS pane1

Lowered support profile for plaster Sealing gasket MDF panel

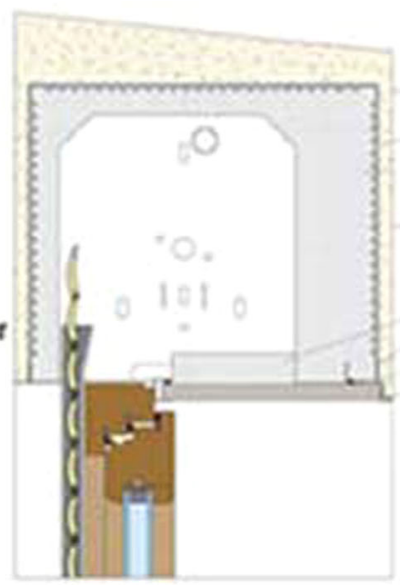

(b)

Plaster

Mortar, sand and cement

with additives

EPS profile

\section{EPS panel}

Lowered support profile fot plaster

Sealing gasket

MDF panel

Fig. 5 a Hyde rolling-shutter box 30-thickness $30 \mathrm{~mm}$, b Hyde rolling-shutter box 35-thickness $35 \mathrm{~mm}$ 
figurations of mounting frame (outer edge wall and inner edge wall) (Fig. 3).

The rolling-shutter boxes with inspection by the bottom, called Hyde, are characterized by having a structure in flame retardant expandable polystyrene of $25 \mathrm{~kg} / \mathrm{m}^{3}$, covered externally with an anchoring network and mortar, sand, and cement admixed with clinging latex, to give maximum set to the application of plaster on the walls. The flap plaster lowered by $2 \mathrm{~cm}$ compared to the profile of the box, allows you to completely hide the front side of the celino, while also serving as support by the inclusion of the same. The sealing gasket in contact with the surface of celino offers improved air tightness and optimal insulation performance. The particular morphology of this type of celino, offers the possibility to thicken considerably the lower insulation, and in some cases, lead to a thickness of the panel in EPS equal to $4 \mathrm{~cm}$. Specifically, two models were analyzed: Hyde 30 (characterized by having a thickness of $30 \mathrm{~mm}$ of EPS), and the model Hyde 35 (characterized by having a thickness of $35 \mathrm{~mm}$ of EPS) (Fig. 5).

\section{Methodology of study}

As previously mentioned the norm, UNI EN 14351-1 Part 1 is the Italian normative reference for the EC marking of transparent windows. The legislation specifies that the value of the thermal transmittance of the window including frame can be obtained either by laboratory testing or by simple calculation according to EN ISO 10077-1, or through finite element calculation according to UNI EN ISO 10077-2 in combination with the simplified calculation.

For the study of rolling-shutter box-frame systems, it was adopted a research methodology complemented by finite element analysis (FEM) and experimental measures on-site. Through the campaign of experimental measurements, it was possible to schematize the numerical model and calibrated FEM.

The structure of the research work can be divided into three main phases:

1. an experimental phase that saw the conductance measurement on-site through the methodology described by the standard prEN 15203 ;

2. validation and calibration of the numerical model FEM schematize for the frame system and of the rollingshutter box system;

3. extension of the FEM analysis for different types of window frames and boxes and calculation of thermal transmittance according to the UNI EN ISO 10077-2;

4. evaluation of improvement hypothesis on the rollingshutter box-frame systems analyzed.

The program used for the schematization of analyzed systems, the FEM analysis and the verification of thermal transmittance is a commercial software: the FRAME SIMULATOR 2 Dartwin in the Student Version.

\section{Experimentation}

The in situ campaign developed at the University of Basilicata, Matera, was to measure the surface temperatures and heat flux on the specific window frame system made in PVC and on the rolling-shutter box system Simply 30. On-site analysis was done by mounting the system on a partition wall between two environments, which were air conditioned in order to create constant thermal difference (Fig. 6).

After adjusting appropriately the climatic parameters of the two rooms in order to achieve a medium $\Delta t$ of about $7^{\circ} \mathrm{C}$, we mounted the frame,

This condition guaranteed, in fact, of detecting the magnitudes (species thermal flows) in the conditions in which they assume higher values. In this way, it was possible to
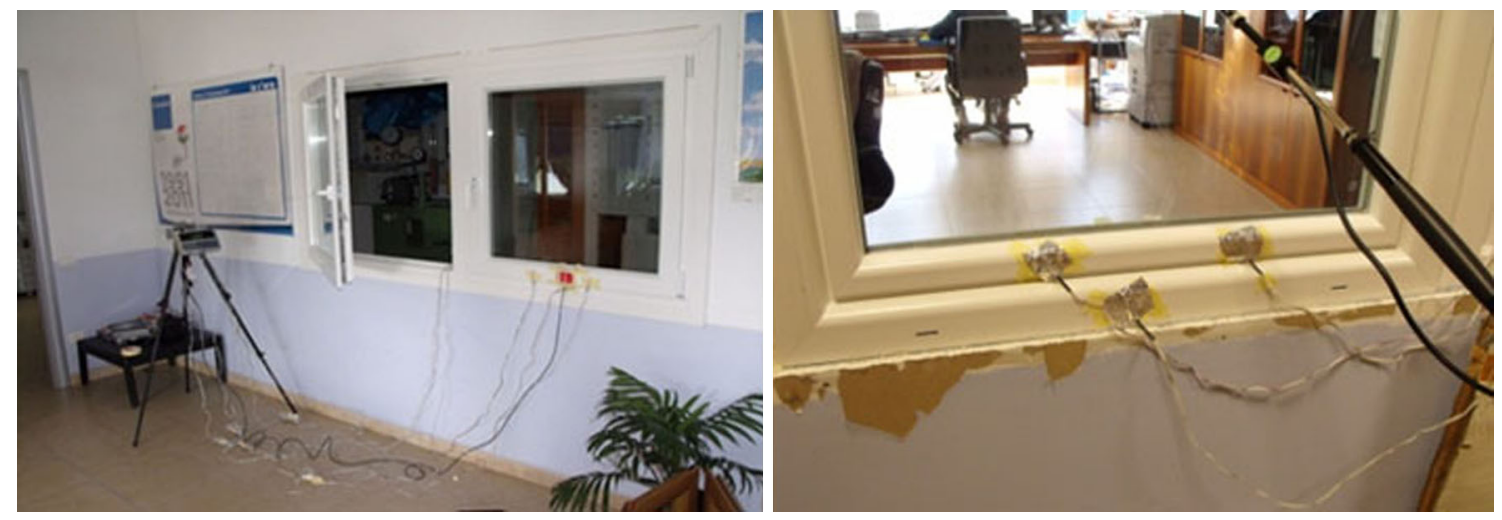

Fig. 6 Installation of the system and sensors for testing on-site 
Table 1 Average values of the thermophysical measurement on the frame

\begin{tabular}{lllll}
\hline $\begin{array}{l}\text { Average temp. } \\
\text { of heated } \\
\text { room }\left({ }^{\circ} \mathrm{C}\right)\end{array}$ & $\begin{array}{l}\text { Average temp. } \\
\text { of conditioned } \\
\text { room }\left({ }^{\circ} \mathrm{C}\right)\end{array}$ & $\begin{array}{l}\text { Average } \\
\text { heat flux } \Phi \\
\left(\mathrm{W} / \mathrm{m}^{2}\right)\end{array}$ & $\begin{array}{l}\text { Conductance } \\
\text { (progressive average } \\
\text { method) }\left(\mathrm{W} / \mathrm{m}^{2} \mathrm{~K}\right)\end{array}$ & $\begin{array}{l}\text { Transmittance (normed surface } \\
\text { resistance normed } \\
\left.0.13 \mathrm{~m}^{2} \mathrm{~K} / \mathrm{W}\right)\left(\mathrm{W} / \mathrm{m}^{2} \mathrm{~K}\right)\end{array}$ \\
\hline 27.05 & 20.35 & 9.6 & 1.689 & 1.173 \\
\hline
\end{tabular}

operate with high output signals from the transducers, obtaining as a result that: the system is less influenced by external disturbances, the measuring instruments operate in ranges significantly greater than the minimum threshold of detection and the changes of the signals are significantly higher than the minimum resolution of the instruments.

Subsequently, through the aid of a multi data logger, four surface temperature sensors and a thermal flow meter, it was initiated the measurement campaign for a period of about 20 days, making a total of 1130 measurements.

The acquired data were processed on-site later with a typical method of systems analysis in transient conditions: the progressive average method.

In the method called "progressive average" or "moving average" one can calculate wall conductance, from the sampled values of surface temperature and heat flux with the following equation:

$C=\frac{\sum_{f=1}^{N} q_{j}}{\sum_{f=1}^{N}\left(T_{\mathrm{Stf}}-T_{\mathrm{SFj}}\right)} \frac{\mathrm{W}}{\mathrm{m}^{2} \mathrm{~K}}$

As $N$ increases, the ratio tends to converge to a stationary value not influenced by the thermal mass of the wall. This can easily be seen from the graph that shows the different values obtained from the calculations; in fact, the function converges with oscillations around a horizontal asymptote with a maximum amplitude of about $0.05 \mathrm{~W} /$ $\mathrm{m}^{2} \mathrm{~K}$.

Through experimental phase, it was possible to validate and calibrate the numerical model FEM and to calculate the error.

The results of measurements on the PVC window frame system were summarized in the following Tables 1 and 2. The first shows the average measured data and the second one describes the difference between the measured conductance in situ and that calculated according to the UNI EN ISO 10077-2 through the application of the FEM method:

As regards, the experimentation on the rolling-shutter box system Simply 35, the measurements returned a conductance value equal to $0.870 \mathrm{~W} / \mathrm{m}^{2} \mathrm{~K}$ compared to a calculated value of $0.835 \mathrm{~W} / \mathrm{m}^{2} \mathrm{~K}$.

\section{Thermal performances of discussed systems}

After having validated the software, it was possible to take the next step of analysis of the thermal transmittance of
Table 2 Measured and calculated thermal transmittance with relative percentage error

\begin{tabular}{lll}
\hline $\begin{array}{l}\text { Measured thermal } \\
\text { transmittance }\left(\mathrm{W} / \mathrm{m}^{2} \mathrm{~K}\right)\end{array}$ & $\begin{array}{l}\text { Calculated thermal } \\
\text { transmittance }\left(\mathrm{W} / \mathrm{m}^{2} \mathrm{~K}\right)\end{array}$ & $\begin{array}{l}\text { Error } \\
(\%)\end{array}$ \\
\hline 1.173 & 1.122 & 4.55 \\
\hline
\end{tabular}

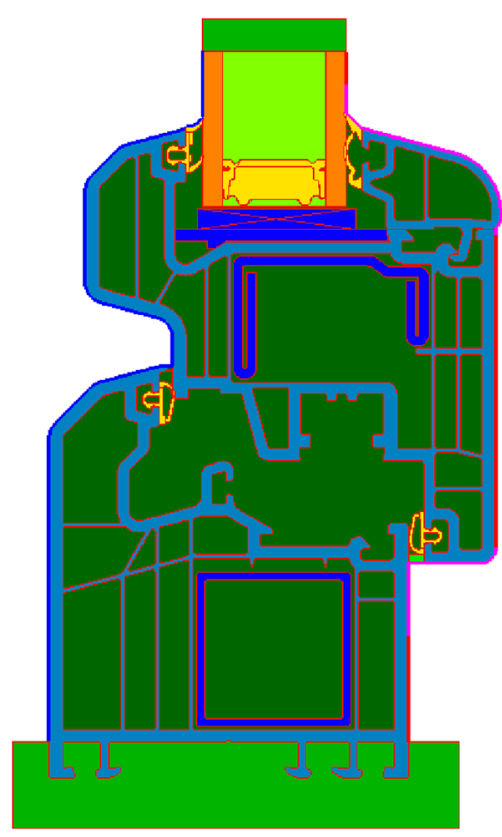

Fig. 7 Schematization of PVC window frame

other types of window frames and similar rolling-shutter boxes. In total, the analyzed systems were eight; of which three windows, two with PVC frame, one with wood frame and one with wood-aluminum frame and four boxes for rolling shutters all in EPS, but with different construction technologies.

Evaluation of window frame system

As regards window frames, once built the numerical model on the software, temperatures and heat flows trends were analyzed and then calculated the value of the thermal transmittance in accordance with the UNI EN ISO 10077-2.

Below there is the schematization of the frame system into the FEM software with the indication of the relative materials placed Fig. 7 .

Materials list in Table 3. 
Table 3 Materials list

\begin{tabular}{|l|c|c|c|c|}
\hline Name & $\begin{array}{c}\lambda \mathrm{x} \\
{[\mathrm{W} / \mathrm{mK}]}\end{array}$ & $\begin{array}{c}\lambda \mathrm{y} \\
{[\mathrm{W} / \mathrm{mK}]}\end{array}$ & $\varepsilon$ & Color \\
\hline EPDM & 0.250 & 0.250 & 0.900 & \\
\hline Stainless steel & 17.000 & 17.000 & 0.900 & \\
\hline Air & 0.106 & 0.115 & 0.900 & \\
\hline PVC & 0.170 & 0.170 & 0.900 & \\
\hline Common glass & 1.000 & 1.000 & 0.900 & \\
\hline Adiabatic & 0.000 & 0.000 & 0.900 & \\
\hline Air & 0.028 & 0.027 & 0.900 & \\
\hline
\end{tabular}

Table 4 Boundary conditions of the FEM model

\begin{tabular}{lll}
\hline & $\begin{array}{l}\text { External boundary } \\
\text { conditions }\end{array}$ & $\begin{array}{l}\text { Internal boundary } \\
\text { conditions }\end{array}$ \\
\hline Temperature & $0.00{ }^{\circ} \mathrm{C}$ & $20.00{ }^{\circ} \mathrm{C}$ \\
Surface resistance & $0.04 \mathrm{~m}^{2} \mathrm{~K} / \mathrm{W}$ & $0.13 \mathrm{~m}^{2} \mathrm{~K} / \mathrm{W}$ \\
\hline
\end{tabular}

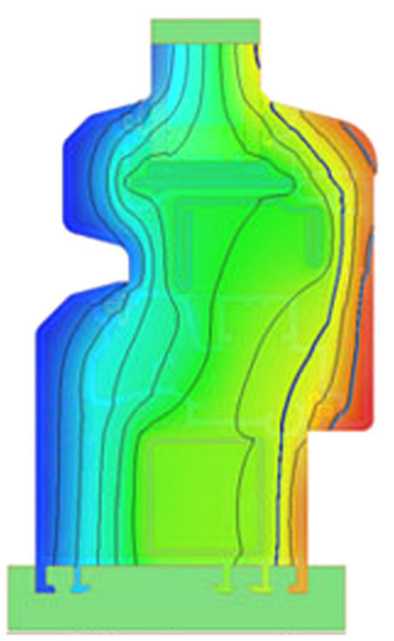

(a) Isothermal

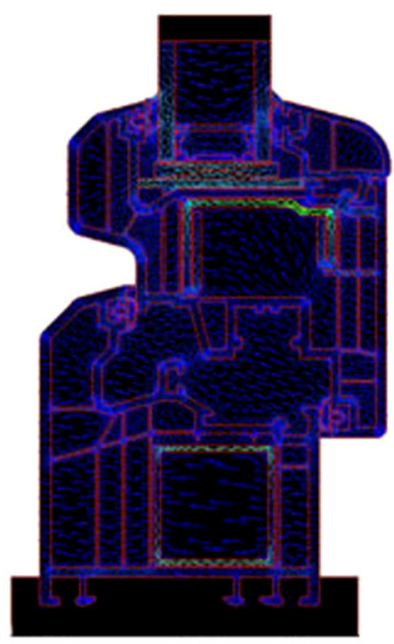

(b) Thermal flux direction
Fig. 8 Values of temperature and heat flux in the PVC frame

As regards the internal and external hypothesized boundary conditions, these are summarized in the table below.

Through the analysis of the temperature and direction of heat flow was possible to study in detail, the structural problems of the frame and joints between fixed and mobile frame, often points of heat loss (Fig. 8).

The calculation of the thermal transmittance, according to the UNI EN ISO 10077-2:2012, returned a value of the thermal transmittance of the only frame Uf equal to
Table 5 Thermal transmittance value

\begin{tabular}{lll}
\hline Model & $\begin{array}{l}\text { Thermal } \\
\text { transmittance } \\
\text { frame uf } \\
\left(\mathrm{W} / \mathrm{m}^{2} \mathrm{~K}\right)\end{array}$ & $\begin{array}{l}\text { Thermal } \\
\text { transmittance } \\
\text { frame/glass uw } \\
\left(\mathrm{W} / \mathrm{m}^{2} \mathrm{~K}\right)\end{array}$ \\
\hline PVC $70 \mathrm{~mm}$ shutter & 1.572 & 1.852 \\
PVC $80 \mathrm{~mm}$ shutter & 1.122 & 1.847 \\
Wood $68 \mathrm{~mm}$ shutter & 1.678 & 2.272 \\
Wood-aluminim 58 mm shutter & 1.618 & 2.053 \\
\hline
\end{tabular}

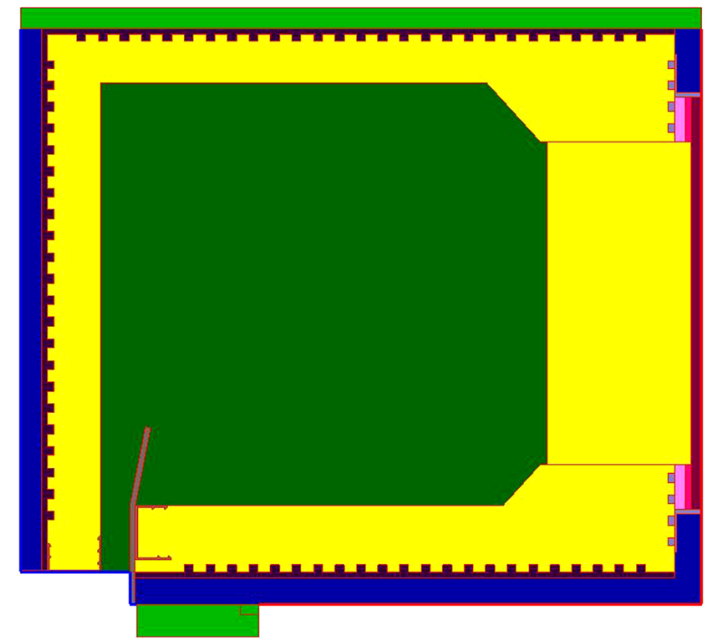

Fig. 9 Schematization of rolling-shutter box with frontal inspection Simply 35

$1.122 \mathrm{~W} / \mathrm{m}^{2} \mathrm{~K}$ and the thermal transmittance of the frame more glass Uw equal to $1.847 \mathrm{~W} / \mathrm{m}^{2} \mathrm{~K}$.

The same procedure was done on other models of frames returning the values summarized in Table 5. 
Evaluation of rolling-shutter box system

Regarding the rolling-shutter boxes, also in this case, after the construction of the numerical model on software, the next step was to analyze the trend of temperatures and heat flows and then calculate the value of the thermal transmittance in accordance with the UNI EN ISO 10077-2.

For the rolling-shutter boxes, the analysis was made with the same constructive material (all are made by EPS), the only changes relate to the different conformations of construction, the different thicknesses of EPS, and the different dispositions of the frame.
For example with regard to the rolling-shutter box system called Simply 35 the analyzes were two, one with the mounting of the frame in correspondence with the external edge of the box and one in correspondence of the inner edge of the box (Fig. 3).

As for the window frame system also for the rollingshutter box system, the first operation was to schematize the FEM software (Fig. 9).

Materials list in Table 6.

The boundary conditions were the same as in the Table 4.

The next step was to analyze the trend of temperatures and heat flux to obtain then the value of the thermal

Table 6 Materials list

\begin{tabular}{|l|c|c|c|c|}
\hline \multicolumn{1}{|c|}{ Name } & $\begin{array}{c}\lambda \mathrm{x} \\
{[\mathrm{W} / \mathrm{mK}]}\end{array}$ & $\begin{array}{c}\lambda \mathrm{y} \\
{[\mathrm{W} / \mathrm{mK}]}\end{array}$ & $\varepsilon$ & Color \\
\hline Adiabatic & 0.000 & 0.000 & 0.900 & \\
\hline $\begin{array}{l}\text { EPS Polystyrene } \\
\text { closed-cell foam }\end{array}$ & 0.034 & 0.034 & 0.900 & \\
\hline $\begin{array}{l}\text { Plasters and } \\
\text { mortars }\end{array}$ & 0.700 & 0.700 & 0.930 & \\
\hline $\begin{array}{l}\text { Mortar of sand and } \\
\text { additivated cement }\end{array}$ & 0.800 & 0.800 & 0.930 & \\
\hline $\begin{array}{l}\text { Unpainted } \\
\text { aluminum }\end{array}$ & 160.000 & 160.000 & 0.300 & \\
\hline PVC-U rigid & 0.170 & 0.170 & 0.900 & \\
\hline Mdf panel & 0.150 & 0.150 & 0.930 & \\
\hline Pe mat & 0.040 & 0.040 & 0.930 & \\
\hline $\begin{array}{l}\text { Magnesium oxide } \\
\text { panel }\end{array}$ & 0.216 & 0.216 & 0.930 & \\
\hline
\end{tabular}

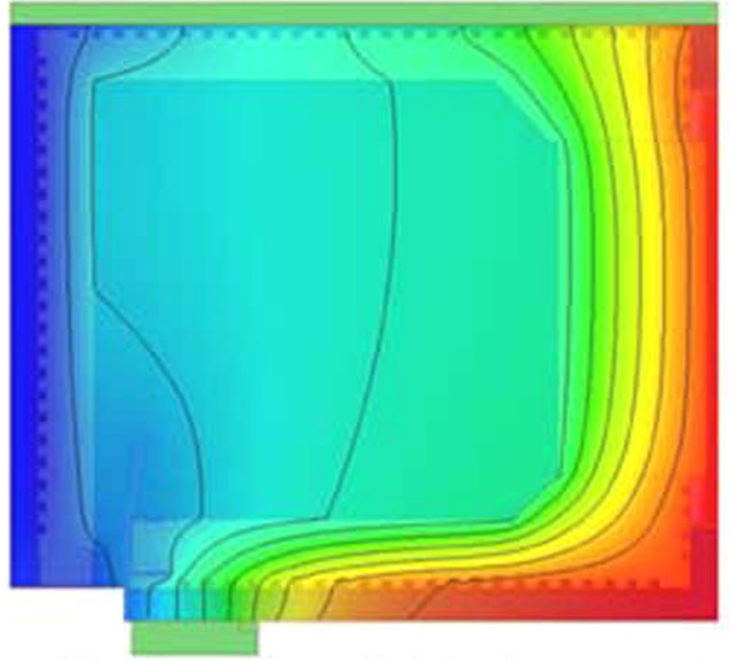

(a) Isothermal Simply 35 shutter external

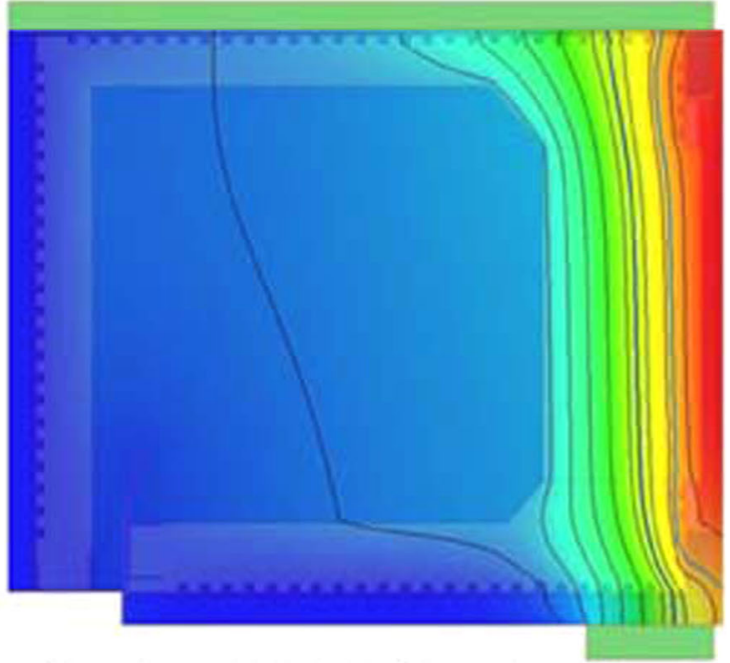

(b) Isothermal Simply 35 shutter internal

Fig. 10 Isoterme Simply 35 with configuration frame outer edge (a) and frame inner edge (b) 
transmittance according to the UNI EN ISO 10077-2. In Fig. 10, the different configurations of the isotherms are shown in the two different cases of the frame installation.

The calculation of the thermal transmittance, according to the UNI EN ISO 10077-2:2012, returned a value of thermal transmittance for the Simply 35 system outer edge of Uf equal to $0.835 \mathrm{~W} / \mathrm{m}^{2} \mathrm{~K}$ and a thermal transmittance value of $0.573 \mathrm{~W} / \mathrm{m}^{2} \mathrm{~K}$ for the Simply system inner edge.

The same procedure was done on other models of boxes and returns the values summarized in Table 7 .

Table 7 Thermal transmittance value

\begin{tabular}{|c|c|c|}
\hline Model & $\begin{array}{l}\text { Thermal transmittance } \\
\text { Uf inner edge }\left(\mathrm{W} / \mathrm{m}^{2} \mathrm{~K}\right)\end{array}$ & $\begin{array}{l}\text { Thermal transmittance } \\
\text { Uf outer edge }\left(\mathrm{W} / \mathrm{m}^{2} \mathrm{~K}\right)\end{array}$ \\
\hline $\begin{array}{l}\text { Simply } 30 \\
\text { EPS } \\
30 \mathrm{~mm}\end{array}$ & 0.838 & 0.945 \\
\hline $\begin{array}{l}\text { Simply } 35 \\
\text { EPS } \\
35 \mathrm{~mm}\end{array}$ & 0.576 & 0.835 \\
\hline $\begin{array}{l}\text { Hide } 30 \text { EPS } \\
30 \mathrm{~mm}\end{array}$ & Not supported & 1.038 \\
\hline $\begin{array}{l}\text { Hide } 35 \text { EPS } \\
35 \mathrm{~mm}\end{array}$ & Not supported & 0.703 \\
\hline
\end{tabular}

Table 8 Thermal transmittance value before and after

\begin{tabular}{llll}
\hline Model & \multicolumn{3}{l}{ Transmittance values Uw } \\
\cline { 2 - 4 } & $\begin{array}{l}\text { Before } \\
\left(\mathrm{W} / \mathrm{m}^{2} \mathrm{~K}\right)\end{array}$ & $\begin{array}{l}\text { After } \\
\left(\mathrm{W} / \mathrm{m}^{2} \mathrm{~K}\right)\end{array}$ \\
\hline PVC $80 \mathrm{~mm}$ shutter & 1.847 & 1.664 & Reduction 10\% \\
Wood 68 mm shutter & 2.272 & 2.000 & Reduction 12\% \\
\hline
\end{tabular}

\section{Analysis of improvements}

The analysis of the improvements was done considering separately the window frame system and the rolling-shutter box system. As regards the window frame system, the improvement was hypothesized for the model of PVC shutter with thickness equal to $80 \mathrm{~mm}$ and for the wooden model. The improvement hypothesis was those of replacement of double glazing with a low-emissivity one and replacement of an air interspace with krypton gas. These two improvements allowed to intervene both on emissivity bringing the value of $\varepsilon$ and from 0.9 to 0.02 and on the conductivity of the interspace halving the value $(\lambda=0.01 \mathrm{~W} / \mathrm{m} \mathrm{K})$. The final results on the window frame system are summarized in the Table 8 .

As regards instead the rolling-shutter box system, the hypothesized improvement was to insert inside the rollingshutter box a thermal reflective insulation composed by a double sheet of aluminum with an interposed inert air bubble made of polyethylene with high density of total thickness equal to $6.5 \mathrm{~mm}$ (Fig. 11).

The final results on the rolling-shutter box system are summarized in the Table 9.

\section{Conclusions}

The commercial finite element method presented in this work, validated by our experimental analysis, is able to appraise, with good accuracy, improvements in thermal performance to be applied to windows and rolling-shutter box systems. Finally, we want to highlight the significant reduction of the thermal transmittance, at least $30 \%$, in the rolling-shutter box systems with the application of a thermal reflective insulation. This last is an innovative material

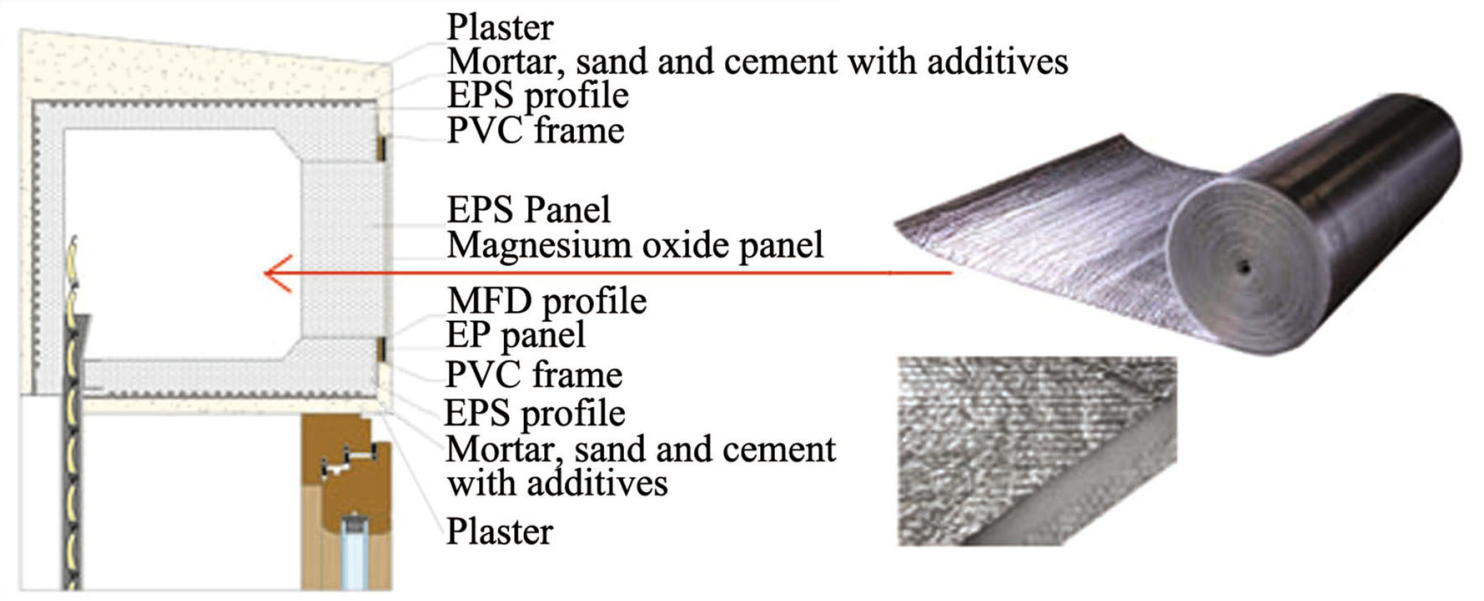

Fig. 11 Hypothesized thermal reflective insulation 
Table 9 Thermal transmittance value before and after

\begin{tabular}{llll}
\hline Model & \multicolumn{3}{l}{ Transmittance values Uf } \\
\cline { 2 - 4 } & Before $\left(\mathrm{W} / \mathrm{m}^{2} \mathrm{~K}\right)$ & After $\left(\mathrm{W} / \mathrm{m}^{2} \mathrm{~K}\right)$ \\
\hline Simply 35 inner edge & 0.576 & 0.400 & Reduction 30\% \\
Simply 30 inner edge & 0.945 & 0.638 & Reduction 32\% \\
Hide 35 outer edge & 0.703 & 0.436 & Reduction 37\% \\
Hide 30 outer edge & 1.038 & 0.701 & Reduction 31\% \\
\hline
\end{tabular}

designed to insulate the walls, but that, as demonstrated by the results obtained in this work, can be effectively used even in the insulation of rolling-shutter box systems.

Open Access This article is distributed under the terms of the Creative Commons Attribution License which permits any use, distribution, and reproduction in any medium, provided the original author(s) and the source are credited.

\section{References}

1. Oleskowicz-Popiel, C., Sobczak, M.: Effect of the roller blinds on heat losses through a double-glazingwindow during heating season in Central Europe. Energ. Build. 73, 48-58 (2014)

2. Shahid, H., Naylor, D.: Energy performance assessment of a window with a hor-izontal Venetian blind. Energ. Build. 37, 836-843 (2005)
3. Esam Alawadhi, M.: Using phase change materials in window shutter to reduce the solar heat gain. Energ. Build. 47, 421-429 (2012)

4. Schultz, J.M., Jensen, K.I., Kristiansen, F.H.: Super insulating aerogel glazing. Sol. Energ. Mater. Sol. Cells. 89, 275-285 (2005)

5. Asdrubali, F., Baldinelli, G., Bianchi, F.: Influence of cavities geometric and emissivity properties on the overall thermal performance of aluminum frames for windows. Energy. Build. 60, 298-309 (2013)

6. Gasparella, A., Pernigotto, G., Cappelletti, F., Romagnoni, P., Baggio, P.: Analysis and modelling of window and glazing systems energy performance for a well-insulated residential building. Energ. Build. 43, 1030-1037 (2011)

7. Seunghwan Yoo, et al.: Thermal transmittance of window systems and effects on building heating energy use and energy efficiency ratings in South Korea. Energ. Build. 67, 236-244 (2013)

8. Gugliermetti, F., Bisegna, F.: Saving energy in residential buildings: the use of fully reversible windows. Energy 32, 1235-1247 (2007)

9. Manz, H., Menti, U.: Energy performance of glazings in European climates. Renew. Energ. 37, 226-232 (2012)

10. Stegou-Sagia, A., et al.: The impact of glazing on energy consumption and comfort. Energ. Convers. Manag. 48, 2844-2852 (2007)

11. Irina Susorova, et al.: The effect of geometry factors on fenestration energy performance and energy savings in office buildings. Energ. Build. 57, 6-13 (2013)

12. Petar Blanusa, et al.: Comparison between ASHRAE and ISO thermal transmittance calculation methods. Energ. Build. 39(3), 374-384 (2007) 